\title{
Inorganic Particles Emulsion Stabilizer and Its Application in Lubricants of Water-Based Drilling Fluids
}

\author{
Tao Zhang ${ }^{a \star}$, Jie Li ${ }^{\mathrm{b} \star}$, Tingting Wang ${ }^{\mathrm{c} \star}$, Fengbao Liu ${ }^{d}$, Baolin Cui ${ }^{\mathrm{e}}$, Lin Zhou ${ }^{\mathrm{f}}$ \\ and Fengshan Zhou ${ }^{g^{*}}$
}

Beijing Key Laboratory of Materials Utilization of Nonmetallic Minerals and Solid Wastes, National Laboratory of Mineral Materials, School of Materials Science and Technology, China University of Geosciences (Beijing), 100083

ª57872221@qq.com, b3202108@163.com, cwttlfmvm1986@163.com, ${ }^{\mathrm{d}}$ liufeng bao100@126.com, e122789004@qq.com, ${ }^{f} 156337848 @ q q . c o m,{ }^{9}$ zhoufs@cugb.edu.cn

$\star$ These authors contributed equally to this work and the manuscript.

"The corresponding author

Keywords: Inorganic particles; Emulsion stabilizer; Corn oil; Wax/Paraffin; Lubricant; Water-Based drilling fluids

\begin{abstract}
Emulsion type lubricants made from mineral oil, animal oil, plant oil and surfactant with its good comprehensive lubrication performances commonly used in water-based drilling fluids. However, the stable preparation techniques and the stability improvement techniques of the emulsions have been the two problems restricting their uses. In this experiment, Through the use of the composite Pickering emulsion stabilizer which consists of two kinds of fine mineral particles fiber chain bunch of attapulgite clay mineral and feather sheet precipitation gas-phase of white carbon black, combined with small amount of chemical emulsifying agent, we can prepare a stability improved microemulsion lubricant with wax/paraffin or corn oil. When using optimized inorganic particles emulsion stabilizer with the quality of the equal proportion of attapulgite, white carbon black(silica) and high viscosity carboxymethyl cellulose(HV-CMC) to prepare microemulsion wax lubricant or microemulsion vegetable oil lubricant, not only reduce the chemical emulsifier dosage in the preparation process, but also greatly improve themechanical stability and storage stability of the emulsions which have good comprehensive lubrication performances. Preparation stable emulsion corn oil lubrication or emulsion wax lubrication with oil phase content more than $40 \%$ just need about $0.3 \% \sim 0.5 \%$ of the composite inorganic particle emulsion stabilizer this paper recommend and 2\% 4\% compound chemical emulsifier. Both of above emulsion lubricants are not stratified during centrifugal ten minutes at $4000 \mathrm{r} / \mathrm{min}$. And both of their sticking coefficient reduced rate $(\Delta \mathrm{Kf})$ and the extreme pressure friction coefficient reduced rate $(\Delta \mathrm{f})$ are more than $70 \%$ in fresh water based drilling fluid at dosage of $1 \%$.
\end{abstract}

\section{Introduction}

Lubricants are one of the most important treatment agents of drilling fluids for deep wells, large displacement wells and horizontal wells. With its good lubrication performance, Mineral oil, animal oil, plant oil, paraffin microemulsion, surfactant emulsion, oil-filled flake graphite, polystyrene pellets, silica microbeads and something else has been more and more widely used in liquid lubricants or solid lubricants. The emulsion lubricant occupies a larger market share in cost-effective of Lubricant products. However, how to prepare stable emulsions (whether paraffin microemulsions, animal oil and plant oil emulsions, or surfactant emulsions) and how to improve the stability of the emulsion in the shortage has been a problem for using. There are also some studies on improving the stability of the emulsion in China, but mostly by increasing the amount of emulsifier, improving the emulsification temperature and emulsification speed and other methods, which undoubtedly increase the drilling fluid lubricant manufacturing and use costs. There have been some studies on using solid particles to prepare stable emulsions in other contries, this type of lotion is called Pickering emulsion, but the domestic application of this research is still insufficient. 
This paper studies micro-inorganic particles, combined with a small amount of emulsifier, prepared as the stability of paraffin and vegetable oil microemulsion used for water-based drilling fluid lubricant. The mechanical stability and storage stability of the emulsion were evaluated by the addition of micro-inorganic particles, and it was found that the stability of the micro-inorganic particles was significantly improved. In the emulsion with the addition of micro-inorganic particles, the emulsion particle size are much smaller than a single by chemical emulsifiers emulsify of emulsion, and less hierarchical. The lubricating property of emulsion lubricant added micro-inorganic particles can basically meet the oil industry industry standards. The micro-inorganic particles have good application prospect as the emulsion stabilizer in the preparation of drilling fluid lubricant.

\section{Materials and Methods}

Instrument. Constant temperature water bath, Three-necked flask, Low speed mixer(1000r/min),High speed mixer(11000r/min),TDL-40B high-speed centrifuge $(10000 \mathrm{r} / \mathrm{min}$, from Shanghai Anting Science Instrument Factory),NF - 2 mud cake adhesion coefficient analyzer and Extreme pressure lubrication instrument(from Qingdao Haitongda Special equipment factory),LA-920 laser scattering particle size distribution instrument(from HORIBA company Japan).

materials. Corn oil(Industrial grade), 58 paraffin(Industrial grade), Paraffin paste(Industrial grade), HV-CMC(Petroleum grade), Precipitated Silica(Industrial grade), Attapulgite (Textile pulp grade), Surfactant(Span80, Tween80, ABS, AES, AS, OP-10, AEO-20, 6501)(CP).

The composition and proportion of laboratory-made emulsifier JL-1, laboratory-made emulsifier JL-4 and laboratory-made inorganic particle emulsion stabilizer A-1 are shown in table 1-table 3.

Table 1 Laboratory-made emulsifier JL-1 recipe (HLB $\approx \mathbf{2 0})$.

\begin{tabular}{cccccccc}
\hline material & $\begin{array}{c}\text { Twe } \\
\text { en80 }\end{array}$ & AES & AS & $\begin{array}{c}\text { OP-1 } \\
0\end{array}$ & 6501 & $\begin{array}{c}\text { AEO } \\
-20\end{array}$ & 水 \\
\hline $\begin{array}{c}\text { composit } \\
\text { ion } / w t \%\end{array}$ & 15 & 10 & 10 & 10 & 3 & 2 & 50 \\
\hline
\end{tabular}

Table 2 Laboratory-made emulsifier JL-4 recipe( HLB $\approx 20)$.

\begin{tabular}{ccccc}
\hline material & Span80 & ABS & Tween80 & OP-10 \\
\hline composition $/ w t \%$ & 55 & 25 & 12.5 & 7.5 \\
\hline Table 3 laboratory-made inorganic particle emulsion stabilizer A-1 recipe & \\
\hline material & ATP & Precipitated Silica & HV-CMC \\
\hline composition $/ w t \%$ & 33.3 & 33.3 & 33.3 \\
\hline
\end{tabular}

Methods. Preparation of corn oil emulsion.(1) According to the HLB value of corn oil is about 20 , and the early screening experiment can determine the emulsified corn oil required emulsifier formula ratio, in this paper, the emulsifier for corn oil was laboratory-made JL-1 emulsifier.(2) The inorganic particle emulsion stabilizer A-1 was prepared by a high speed mixer to form a suspension with a mass concentration of $1.5 \%, 2.5 \%$ and $3 \%$, and hydrated for 1 day.(3)Then prepare corn oil emulsion of oil-water ratio is $4: 1$ in the water. The specific preparation process is: at first, weighed $20 \mathrm{~g}$ of Hydrated suspensions, added appropriate amount of emulsifier to to the hydrated suspension, stirredevenly, and then $80 \mathrm{~g}$ of corn oil divided into three times was added to the aqueous phase, the temperature was controlled at $50^{\circ} \mathrm{C}$ (also can be controlled at room temperature), stirred at high speed for $30 \mathrm{~min}$, stirred and cooled to room tempreture.

Preparation of Paraffin Microemulsion. (1)According to the HLB value of paraffin is about 10, 
and the early screening experiment can determine the emulsified paraffin required emulsifier formula ratio, in this paper, the emulsifier for paraffin was laboratory-made JL-4 emulsifier.(2) The inorganic particle emulsion stabilizer A-1 was prepared by a high speed mixer to form a suspension, and hydrated for 1 day.(3) The paraffin emulsion was prepared in water. The specific preparation process is: weighed a certain amount of Hydrated suspensions as the stabilizer, the emulsifier is added to the hydrated suspension in an appropriate amount. srirredevenly. Heated the 58 paraffin blocks and paraffin paste to $60^{\circ} \mathrm{C}$ and mixed them together. Then add $2 \mathrm{~g} \mathrm{NaOH}$ to do the pre-reaction, and then added the aqueous phase into the molten paraffin solution in batches, the temperature was controlled at $80^{\circ} \mathrm{C}$, constant temperature and high-speed stirring 30min, and finally, stirred and cooled to room tempreture.

\section{Results and Discussion}

Stability of Corn Oil Emulsion. In the case where no stabilizer was added, emulsifier JL-1 were added at different concentrations. It can be seen that in the absence of the addition of stabilizer, the corn oil emulsion can be stored for a long period of time when the amount of emulsifier is $4 \%$, and the oil-water phase is not precipitated after standing for a long period of time, but under the influence of high-speed centrifugation oil and water phase is still relatively easy to precipitate by measuring its its storage stability(storage stability refers In the room temperature conditions for a certain period of time stratification situation of emulsion oil and water.) and the mechanical stability.(Mechanical stability refers under the conditions of centrifugal treatment in $4000 \mathrm{r} / \mathrm{min}$ in $10 \mathrm{~min}$,the precipitation situation of water and oil in the emulsion. The data are shown in Table 4 below.

Table 4 Effect of the addition of emulsifier JL-1 on the stability of corn oil emulsion

\begin{tabular}{cccc}
\hline \multirow{2}{*}{$\begin{array}{c}\text { Addition of JL-1 } \\
(w t / v, \%)\end{array}$} & storage stability & \multicolumn{2}{c}{ mechanical stability $/ \mathrm{mL}$} \\
\cline { 3 - 4 } 1.0 & 0.5 day & 13 & precipitation of water \\
2.0 & 0.5 day & 13 & 4 \\
3.0 & $>7$ days & 11 & 4 \\
4.0 & $>7$ days & 7 & 4 \\
5.0 & $>7$ days & 9 & 4 \\
\hline
\end{tabular}

The stability of the emulsion was determined by changing the concentration of the stabilizer suspension as shown in table 5. It can be seen from the table that when the concentration of the stabilizer suspension is at $1.5 \%$ ( i.e.the actual pure stabilizer A-1 content is only $0.3 \%$ of the total mass of the emulsion system), It can play a good stabilizing effect on corn oil emulsion, $t$ can be concluded that the stability of the emulsion can be improved greatly, and there is no water phase and oil phase separation after centrifugation treatment

Table 5 Effect of the addition of stabilizer A-1 on the stability of corn oil emulsion

\begin{tabular}{|c|c|c|c|c|}
\hline \multirow{2}{*}{$\begin{array}{c}\text { addition of } \\
\text { stabilizer A-1 } \\
(w t / v, \%)\end{array}$} & \multirow{2}{*}{$\begin{array}{c}\text { addition of } \\
\text { emulsifier JL-1 } \\
(w t / v, \%)\end{array}$} & \multirow[b]{2}{*}{ storage stability } & \multicolumn{2}{|c|}{ mechanical stability $/ \mathrm{mL}$} \\
\hline & & & $\begin{array}{l}\text { precipitatio } \\
\mathrm{n} \text { of water }\end{array}$ & $\begin{array}{l}\text { precipitatio } \\
\mathrm{n} \text { of oil }\end{array}$ \\
\hline 0.3 & 4.0 & $>7$ days & microscale & microscale \\
\hline 0.5 & 4.0 & $\begin{array}{l}\text { Viscous, not } \\
\text { flowing }\end{array}$ & - & - \\
\hline 0.6 & 4.0 & $\begin{array}{l}\text { Viscous, not } \\
\text { flowing }\end{array}$ & - & - \\
\hline
\end{tabular}

In the emulsion, the addition of an inorganic particle stabilizer can greatly reduce the amount of 
emulsifier but the effect on the stability of the emulsion is little (see Table 6). It can be seen from the table 6 that the addition of inorganic particle stabilizer not only reduces the amount of emulsifier, but also improves the stability of corn oil emulsion. And the inorganic particle stabilizer has a low cost and a small amount of additive, which can achieve good stability when the amount of emulsion is about $0.3 \%$.

Table 6 Effect of the addition of the stabilizer on the addition of the emulsifier

\begin{tabular}{ccccc}
\hline $\begin{array}{c}\text { Addition of } \\
\text { emulsifier JL- } \\
(w t / v, \%)\end{array}$ & $\begin{array}{c}\text { addition of } \\
\text { stabilizer A-1 } \\
(w t / v, \%)\end{array}$ & $\begin{array}{c}\text { storage } \\
\text { stability }\end{array}$ & $\begin{array}{c}\text { mechanical stability } / \mathrm{mL} \\
\text { precipitati }\end{array}$ & $\begin{array}{c}\text { precipitati } \\
\text { on of oil }\end{array}$ \\
\hline 0.3 & 0.3 & 0.5 day & 3.0 & - \\
0.5 & 0.3 & 0.5 day & Trace & - \\
1.0 & 0.3 & $>7$ days & - & - \\
2.0 & 0.3 & $>7$ days & - & - \\
3.0 & 0.3 & $>7$ days & - & - \\
\hline
\end{tabular}

Fig. 1 is a micrograph of corn oil microemulsion with volume ratio of $\mathrm{V}$ corn oil: $\mathrm{V}_{\text {water }}=4: 1$. It can be seen that the emulsion droplets minimum particle size less than 1um, but also the greatest 40um, Some small particles with small diameter were attached to the surface of the droplet, which is estimated that the inorganic nanometer mineral stabilizer is attached to the droplet surface, thus played a role in enhancing the mask.

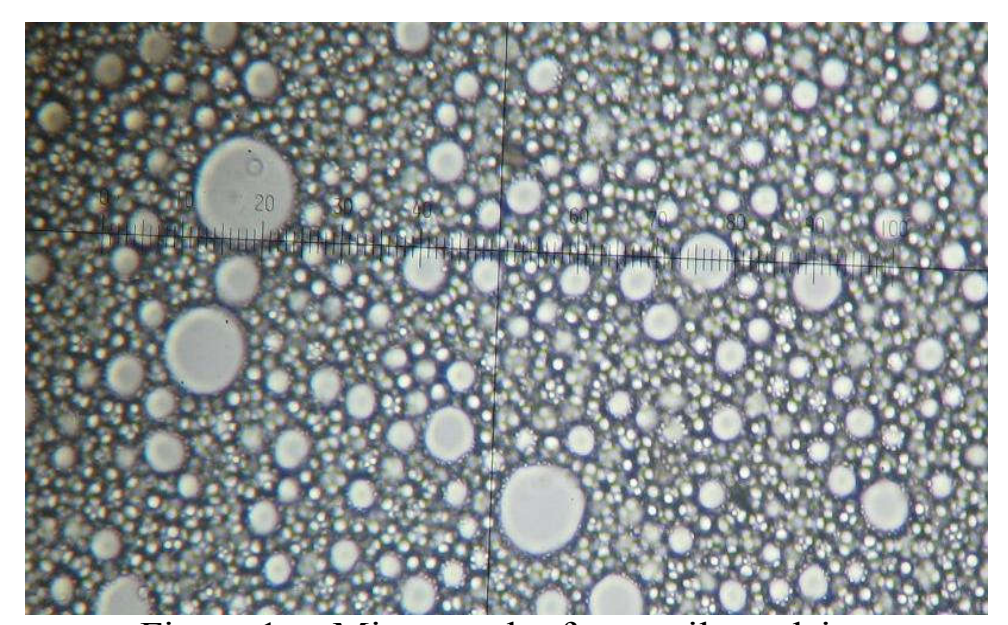

Figure 1. Micrograph of corn oil emulsion

Stability of Paraffin Microemulsion. Paraffin emulsion was prepared by L9 (34) orthogonal experimental design (Table 7), 9 groups of samples prepared by only $71^{\#}, 72^{\#}, 76^{\#}, 77^{\#}$ and $78^{\#}$ static stratification, the rest of the sample is not too high viscosity, or delamination. 
Table 7 L9 (34) orthogonal experimental design and emulsion stability of emulsion paraffin.

\begin{tabular}{|c|c|c|c|c|c|c|c|}
\hline \multirow{2}{*}{$\begin{array}{l}\text { experime } \\
\text { nt number }\end{array}$} & \multicolumn{4}{|c|}{$\begin{array}{c}\text { composition of emulsion } \\
\text { paraffin }(w t / v, \%) \text { (The rest is } \\
\text { water) }\end{array}$} & \multirow{2}{*}{$\begin{array}{l}\text { storage } \\
\text { stability }\end{array}$} & \multicolumn{2}{|c|}{ mechanical stability /mL } \\
\hline & $\begin{array}{l}\mathrm{JL} \\
-4\end{array}$ & $\begin{array}{c}\text { A } \\
-1\end{array}$ & $\begin{array}{l}\text { paraff } \\
\text { in }\end{array}$ & $\begin{array}{l}\text { paraff } \\
\text { in paste }\end{array}$ & & $\begin{array}{l}\text { precipitatio } \\
\text { n of water }\end{array}$ & $\begin{array}{l}\text { precipitatio } \\
\mathrm{n} \text { of oil }\end{array}$ \\
\hline 71 & 1 & $\begin{array}{l}0 . \\
4\end{array}$ & 10 & 20 & $>7$ days & $2 \sim 4$ & - \\
\hline 72 & 1 & 5 & 15 & 25 & $>7$ days & - & - \\
\hline 73 & 1 & 6 & 20 & 30 & & & \\
\hline 74 & 2 & 6 & 10 & 25 & & & \\
\hline 75 & 2 & $4^{0 .}$ & 15 & 30 & & & \\
\hline 76 & 2 & 5 & 20 & 20 & $>7$ days & - & - \\
\hline 77 & 3 & 5 & 10 & 30 & $>7$ days & - & - \\
\hline 78 & 3 & 6 & 15 & 20 & $>7$ days & 10 & - \\
\hline 79 & 3 & $\begin{array}{l}0 . \\
4\end{array}$ & 20 & 25 & & & \\
\hline
\end{tabular}

From the above experiments, it can be found that in the preparation of paraffin microemulsion, the amount of solid particles stabilizer can not exceed $0.5 \%$, otherwise it will lead to excessive viscosity of the emulsion and thus the loss of liquidity, so taking into account the cost factors, 72 \# and $76^{\#}$ more suitable for the preparation of paraffin emulsion.

Fig. 2 shows the laser particle size distribution of the 76 \# emulsion paraffin sample. As can be seen from the figure, the particle size of the paraffin emulsion is roughly between $200 \mathrm{~nm}$ and $10 \mu \mathrm{m}$. As can be seen from the particle size distribution, the emulsified paraffin prepared in the experiment has a small particle size, it can show a good dispersion phenomenon in the base slurry and drilling fluid, when the drilling fluid is added into the formation, the paraffin particles can penetrate the pores of the formation, It can play a role in the formation of nano-micron paraffin plugging pore formation, maintaining the stability of the stratum.

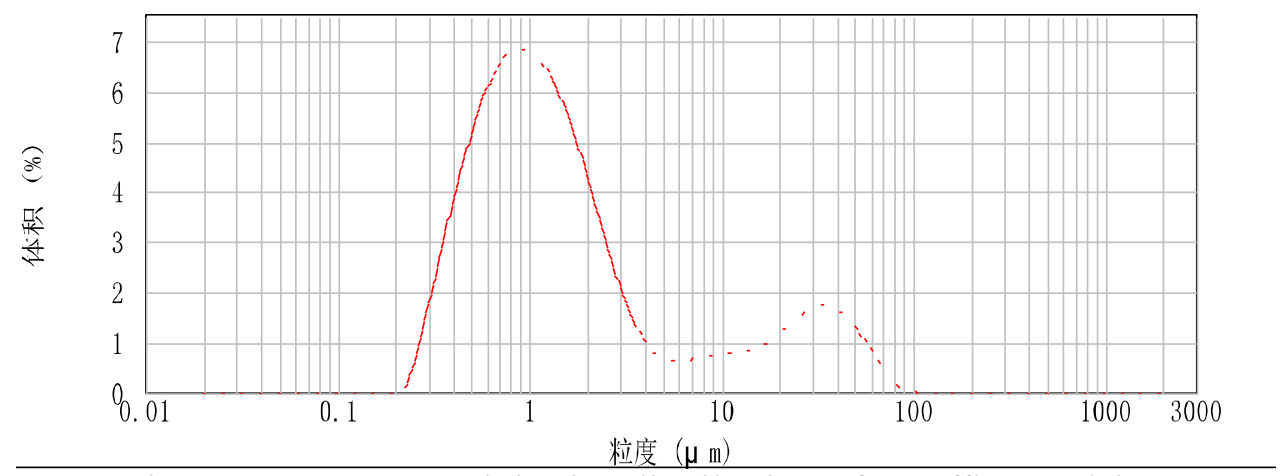

Figure 2. Laser particle size distribution of paraffin emulsion

Lubricant performance evaluation method of corn oil emulsion (E oil) and paraffin microemulsion (Ewax) reference to China Petroleum Corporation in 2012 the latest release of "Q/SY 1088-2012 drilling fluid with a liquid lubricant technology standard", industry standard. $1.0 \%$ of the lubricant 
samples were added to the prepared freshwater base slurry with high-speed stirring, the adhesion coefficient reduction rate $\Delta K_{f}$ and the friction coefficient reduction rate $\Delta f$ were tested for each sample and sold to the same lubricant Product performance for a comprehensive comparison (Table 8). It can be seen that the synthetic lubricating properties of the corn oil emulsion (E oil) and the paraffin wax (Ewax) prepared in this paper has some better properties in lubricity compared with other contrast lubricants of the emulsion type, but the stability of E oil and Ewax emulsion is better, and the preparation cost is lower.

It can also be seen from the experimental data in Table 8 that the overall performance of the two full-oil phase lubricants is more excellent than the overall performance of the sample, and that the overall oil phase lubricant is significantly better in the actual drilling process than the emulsion type lubricant, But its production costs are much higher than the emulsion type lubricant.

Table 8 Comparison of Lubricant Properties of Several Water-based Drilling Fluid Lubricant Samples ( $1 w t \%$ Addition)

\begin{tabular}{|c|c|c|c|c|c|c|}
\hline $\begin{array}{l}\text { sampl } \\
\text { e }\end{array}$ & origin & $\begin{array}{c}\text { main } \\
\text { components of } \\
\text { lubricant }\end{array}$ & $\begin{array}{l}\text { granulari } \\
\text { ty level }\end{array}$ & $\begin{array}{r}\text { product } \\
\text { appearance }\end{array}$ & $\underset{/ \%}{\Delta K_{f}}$ & $\underset{1 \%}{\Delta f}$ \\
\hline $\mathrm{E} \mathrm{oil}^{\mathrm{a}}$ & $\begin{array}{l}\text { this } \\
\text { article }\end{array}$ & $\begin{array}{l}\text { corn oil } \\
\text { emulsion }\end{array}$ & $\begin{array}{l}\text { micron } \\
\text { level }\end{array}$ & $\begin{array}{l}\text { multiphas } \\
\text { e emulsion }\end{array}$ & 78.2 & $\begin{array}{l}75 . \\
4\end{array}$ \\
\hline $\operatorname{Ewax}^{\mathrm{a}}$ & $\begin{array}{l}\text { this } \\
\text { article }\end{array}$ & $\begin{array}{l}\text { Paraffin wax } \\
\text { emulsion }\end{array}$ & $\begin{array}{c}\text { nano } \\
\text { microns } \\
\text { level }\end{array}$ & $\begin{array}{l}\text { multiphas } \\
\text { e emulsion }\end{array}$ & 73.5 & $\begin{array}{l}77 . \\
6\end{array}$ \\
\hline$\underset{\mathrm{b}}{\mathrm{WDZ}}$ & $\begin{array}{l}\text { Dezho } \\
\text { u }\end{array}$ & $\begin{array}{l}\text { emulsified } \\
\text { paraffin }\end{array}$ & $\begin{array}{l}\text { nano } \\
\text { level }\end{array}$ & $\begin{array}{c}\text { two - } \\
\text { phase } \\
\text { emulsion }\end{array}$ & 65.3 & $\begin{array}{l}72 . \\
5\end{array}$ \\
\hline$\underset{b}{\mathrm{WDY}}$ & $\begin{array}{l}\text { Dongy } \\
\text { ing }\end{array}$ & $\begin{array}{l}\text { emulsified } \\
\text { paraffin }\end{array}$ & $\begin{array}{l}\text { nano } \\
\text { level }\end{array}$ & $\begin{array}{l}\text { two - } \\
\text { phase } \\
\text { emulsion }\end{array}$ & 71.5 & 33. \\
\hline$\underset{b}{\text { Slube }}$ & $\begin{array}{l}\text { Binzh } \\
\text { ou }\end{array}$ & $\begin{array}{l}\text { Oil-filled } \\
\text { expansive flake } \\
\text { graphite }\end{array}$ & $\begin{array}{l}\text { nano } \\
\text { microns } \\
\text { level }\end{array}$ & loose solid & 57 & 64 \\
\hline$\underset{\mathrm{b}}{\mathrm{GD}-2}$ & $\begin{array}{l}\text { Renqi } \\
\mathrm{u}\end{array}$ & $\begin{array}{l}\text { oil-filled flake } \\
\text { graphite }\end{array}$ & $\begin{array}{c}\text { nano } \\
\text { microns } \\
\text { level }\end{array}$ & loose solid & 26.3 & 65 \\
\hline$\underset{b}{\text { Q-Dri }}$ & $\begin{array}{l}\text { Dongy } \\
\text { ing }\end{array}$ & $\begin{array}{l}\text { oil-based } \\
\text { surfactants }\end{array}$ & $\begin{array}{l}\text { whole oil } \\
\text { phase }\end{array}$ & $\begin{array}{l}\text { homogene } \\
\text { ous liquid }\end{array}$ & 83.7 & $\begin{array}{l}83 . \\
3\end{array}$ \\
\hline $\begin{array}{l}\text { MHR } \\
-86^{b}\end{array}$ & $\begin{array}{l}\text { Shang } \\
\text { hai }\end{array}$ & $\begin{array}{l}\text { oil-based } \\
\text { surfactants }\end{array}$ & $\begin{array}{l}\text { whole oil } \\
\text { phase }\end{array}$ & $\begin{array}{l}\text { homogene } \\
\text { ous liquid }\end{array}$ & 81.6 & $\begin{array}{l}75 . \\
4\end{array}$ \\
\hline $\begin{array}{l}\text { Liq-L } \\
\text { ube s }\end{array}$ & $\begin{array}{l}\text { Hangb } \\
\text { iao }\end{array}$ & - & - & liquid & 50 & 80 \\
\hline
\end{tabular}

Note: in this table a is an optimized sample prepared in this paper, $\mathrm{b}$ is a commercially available comparative sample, and $\mathrm{s}$ is an industry standard for liquid lubricant requirements.

Mechanism of Synergistic Emulsification of Inorganic Nanoparticles. Pickering Emulsifier and Pickering Emulsion. As early as the beginning of the 20th century, Pickering [19] first discovered colloidal size solid particles that could stabilize the emulsion as an emulsifier. He uses copper sulfate, ferric sulfate to stabilize water and paraffin systems. He uses copper sulfate, ferric sulfate to stabilize water and paraffin systems. The crude oil emulsion system was separated by Masliyah[20] and others for first time. The clay particles, $\mathrm{SiO} 2$ particles and so on were obtained, when studies the role of these solid particles in emulsion stabilization, it is found that these solid particles can greatly improve the agglomeration stability of the emulsion. In recent years, with the 
progress of nanotechnology, nano-solid particles on the stability of the emulsion research has gradually in-depth

In some areas, these solid particles can replace the traditional surfactant or reduce the amount of surfactant in order to achieve the purpose of reducing costs. The fine solid particles used to replace the traditional chemical emulsifier are called Pickering emulsifiers and the emulsions prepared with Pickering Emulsifier as the main emulsifier are referred to as Pickering emulsions. Pickering Emulsion has now been widely used in cosmetics, food, medicine, asphalt and various industrial emulsion systems.

Fully hydrated clay mineral particles are excellent Pickering emulsifiers. Fully hydrated layered and fibrous clay mineral particles as well as various nano-micron inorganic powder materials are excellent Pickering emulsifiers. This fine solid phase particles form a thin film on the surface of the dispersed phase droplets to prevent the aggregation between the droplets, therefore, stable $\mathrm{O} / \mathrm{W}$ and $\mathrm{W} / \mathrm{O}$ dispersions can be prepared. When the fine solid particles are used as the emulsifier, the stability of the emulsion depends on the particle size of the solid particles, the surface wettability and the interaction between the solid particles, in which the wettability of the particle surface is the most important influencing factor.

In the preparation of emulsified paraffin and emulsified corn oil, synergistic emulsification of solid particles can also be used. The solid particles have the effect of increasing the viscosity of the aqueous phase when the clay particles, such as bentonite, argonite, attapulgite and other clay minerals, are added in the reaction system. The better the emulsion viscosity is, the better the stability, But also consider the fluidity of the emulsion product, select the appropriate amount, that is, the critical concentration. The key to co-emulsification of solid particles is the critical particle concentration. When the solid particle concentration is below the critical value, the droplet size of the emulsion decreases with the increase of the solid particle concentration, and the particle size of the emulsion does not change when the solid particle concentration reaches or exceeds this concentration.

Nano-micron inorganic powder particles are also excellent Pickering emulsifiers. Binks ${ }^{[21]}$ et al. prepared a stable emulsion with an oil / water volume ratio of 50:50 with partially hydrophobic monodisperse $\mathrm{O} / \mathrm{W}$ nanoparticles. The addition of an appropriate amount of surfactant can promote the production of particulate flocs, thereby enhancing emulsion stability. Some scholars have studied the emulsification ability of two kinds of oil phase (paraffin oil and cooked vegetable oil) with PEO chain series surfactants and $\mathrm{SiO}_{2}$ particles. It was found that the adsorption of $\mathrm{SiO}_{2}$ particles on the interface of oil and water is mainly composed of single layer. Solid particles (especially fine particles such as fumed silica produced by precipitation) can be irreversibly adsorbed at the oil-water interface, which can produce large steric hindrance and effectively reduce the probability of collision of particles, resulting in direct stabilization of the emulsion.

On the other hand, on the interface where the surfactant has been adsorbed, the solid particles can be reabsorbed to achieve the purpose of the coordination of the emulsion stability If the particles in the oil-water interface or near the interface formed a strong network structure, so that the role between the particles become stronger, a higher strength of the viscoelastic membrane would be formed at the interface, solid particles in the retention between the droplets can also Inhibit the aggregation, delamination or precipitation of emulsion droplets, thereby further reducing the probability of emulsion coalescence. In addition, the network structure formed by the dispersion of the particles can increase the bulk viscosity of the emulsion, thereby greatly reducing the rate of oil-water separation.

Different morphology of composite nano-micron inorganic particles is the ideal Pickering emulsifier. The attapulgite in the inorganic particle stabilizer used in this experiment belongs to the fiber chain bundle mineral. It is able to dissolve and unfold after full hydration, and the attapulgite fibers are wrapped on the surface of the emulsion particles during the emulsification process, which enhances the strength of the liquid film, thus slowing down the aging rate of the emulsion and improving the emulsion stability. Precipitated silica with the large surface area, small particles, can also enhance the liquid film strength, it is generally feather-like. Hv-CMC can moderately increase the viscosity of the emulsion, so it also plays a role in stabilizing the emulsion. Multi-morphological 
composite nano-micron inorganic particles play a different role in the success of the preparation of cost-effective stability of the emulsion-type drilling fluid lubricant is essential.

\section{Conclusions}

The use of fine inorganic particles attapulgite and silica, combined with a small amount of emulsifier, Can produce a significant increase in stability of the emulsion-based water-based drilling fluid lubricant.

The paraffin microemulsion and the plant oil microemulsion prepared by the attapulgite: silica: high viscose carboxymethylcellulose in the mass percentage of 1: 1: 1 emulsion stabilizer not only reduce the amount of emulsifier added, but also Greatly improving the mechanical stability of the emulsion and storage stability, and has a good overall lubrication performance.

The composite nanosized inorganic particles of different morphology are ideal Pickering emulsifiers and only $0.3 \%$ to $0.5 \%$ inorganic microparticle emulsion stabilizer in the preparation of stable corn oil emulsion or paraffin emulsion lubricant with oil content greater than $40 \%$.

\section{Conflict of Interests}

The authors declare that there is no conflict of interests regarding the publication of this paper.

\section{Acknowledgements}

Thanks for this research work was supported by The National Key Technology R\&D Program of China (2014BAC31B01).

\section{References}

[1] Ryen Caenn, HCH Darley, George R. Gray. Composition and Properties of Drilling and Completion Fluids[M], Sixth Edition [M]. Massachusetts:Gulf Professional Publishing, 2011,551-558.

[2] Yingxiao. preparation of animal and vegetable fats and anti-high temperature lubricant for drilling fluid [p]. CN101157850,2008-04-09

[3] Daohan Zhao, Chen Juan, Qinglin Sun, et al. study and evaluation of water base drilling fluid lubricant NSR-1 [j]. Oilfield chemicals, 2007,24 (2): 97-99.

[4] Daohan Zhao, Chen Juan, Qinglin Sun, et al. study and evaluation of water base drilling fluid lubricant NSR-1 [j]. Oilfield chemicals, 2007,24 (2): 97-99.

[5] Chen, Wang, Yuanpeng Gao, et al. paraffin Nano-emulsion drilling fluid technology and its application in horizontal well [j]. drilling fluids and completion fluids, 2010,27 (4): 87-89.

[6] Yan Zhang, yan Liu. application of elastic graphite to drilling fluid [j]. the natural gas industry, 2003,23 (1): 42-44.

[7] Dongshi Geng, weigong chen, Shuqing Sun, etc.-solid lubricant for drilling fluid research and application of plastic pellets [j]. chemical, 1993,10 (2): 169-172.

[8] Halliday William S, Clapper Dennis K. Purified paraffins as lubricants, rate of penetration enhancers, and spotting fluid additives for water-based drilling fluids[P],US Pat.5837655,1998-11-17 .

[9] Xin Zhang. high stability of emulsified paraffin preparation methods [p]. CN02109958.8,2007-03-21. 
[10] liyang Dai, Hongjun Li, Xiuchun Su, et al. study on preparation and stability of nanometer paraffin wax emulsion [j]. Petro-chemical applications, 2011, (30) 3:23-27.

[11]Kenneth Klein.Improve the stability of the emulsion[J].Daily Chemical Industry Translation, 1985,(2):46.

[12] Tao wu, Dejun,sun.Synthesis of Paraffin Emulsion WPE and Its Application in Dispersed System[J].Journal of Shandong University (Science Edition),2006,41(4):141-144.

[13] Dejun sun.A particle stabilizing emulsion system and its preparation method and application as a drilling fluid lubricant[P].CN1699500A,2005-11-23.

[14] Liyuan.Research and Application of Nano - drilling Fluid Treatment Agent[D].Qing dao:The University of China Ocean ,2006.

[15] Yetian.Research and Application of Emulsified Paraffin for Oil Well Drilling Fluid Completion[D].Beijing:Beijing University of Chemical Technology,2008.

[16]Qianglan.Surfactant Substrates Stabilized Pickering Emulsion with Nanoparticles[D].jinan:College of Chemistry and Chemical Engineering, Shandong University,2007.

[17]Feiyang,Junwnag,Qianglan,Dejun sun,etc. Research Progress of Pickering Emulsion[J].Chemical progress,2009,21(0708): 1418-1426.

[18]China National Petroleum Corporation. Enterprise Standard Q / SY 1088-2012. Technical specification for liquid lubricants for drilling fluids, 2012.

[19] S.U. Pickering. Emulsions [J],J. Chem. Soc. 1907,91:2001-2021.

[20] N.X.Yan, J.H.Masliyah. Characterization and demulsification of solids-stabilized oil-in-water emulsions Part 1.Partitioning of clay particles and preparation of emulsions [J]. Colloids Surf. Anal. 1995,96:229-242.

[21]B.P.Binks, S.O.Lunsdon. Influence of Particle wettability on the type and stability of Surfactant-free emulsions[J]. Langmuir. 2000(16):8622-8631. 